\title{
Static Secondary Ionization Mass Spectrometry Analysis of Tributyl Phosphate on Mineral Surfaces: Effect of Fe(II)
}

\author{
Gary S. Groenewold, Jani C. Ingram, James E. Delmore, and \\ Anthony D. Appelhans \\ Idaho National Engineering Laboratory, P.O. Box 1625, Idaho Falls, Idaho, USA
}

The static secondary ionization mass spectrometry (SIMS) spectrum of tri- $n$-butyl phosphate
(TBP) on a variety of basalt and quartz samples is affected by the chemical composition of
the mineral surface. When TBP is adsorbed on Fe(II)-bearing surfaces, the compound
undergoes concomitant $\mathrm{H}^{-}$abstraction and reduction, followed by the elimination of two
$\mathrm{C}_{4} \mathrm{H}_{8}$ molecules to form an ion at $m / z 137^{+}$. When TBP is adsorbed to quartz or other
nonreducing surfaces, it merely undergoes protonation and elimination of three $\mathrm{C}_{4} \mathrm{H}_{8}$
molecules to form $\mathrm{H}_{4} \mathrm{PO}_{4}^{+}$. When TBP is adsorbed to Fe(III)-bearing surfaces, it undergoes
$\mathrm{H}^{-}$abstraction and elimination of two $\mathrm{C}_{4} \mathrm{H}_{8}$ molecules, to form an ion at $\mathrm{m} / z 153^{+}$. These
conclusions are supported by model studies that employed $\mathrm{FeO}, \mathrm{Fe}_{2} \mathrm{O}_{3}, \mathrm{TBP}$, and tributyl
phosphite. The results show that the SIMS spectrum is very sensitive to the mode of TBP
adsorption on the mineral surface. (J Am Soc Mass Spectrom 1995, $6,165-174$ )

$O^{b}$ econdary ionization mass spectrometry (SIMS) has been used to characterize contaminants adsorbed to surfaces, but is generally considered insensitive to the orientation or adsorption of surface species because it is a high energy technique. This view is consistent with experiments that employ energetic (kilovolt) atomic primary ion guns that are operated at microamps of current: excellent elemental analyses and elemental depth profiling are achieved, but little molecular information from the top monolayer is generated. Molecular species can be observed in SIMS by using an atomic primary particle at lower beam current (i.e., by employing static SIMS conditions), but little is known about the relationship between the secondary ions observed and the nature of the adsorbed surface molecules. In the present paper we show that SIMS with a molecular primary ion, operated at picoamps of current, is sensitive not only to the presence of surface molecules, but also sensitive to their mode of adsorption. This indicates that at least in some cases, static SIMS is useful for understanding contaminant-surface interactions, which in the environment are important because they control transport, degradation, and remediation chemistries. The system presently under study is tri-n-butyl phosphate (TBP) on basalt and quartz.

The detection of TBP on mineral surfaces is being investigated because TBP has been used extensively for the extraction of uranium and plutonium as nitrate

Address reprint requests to Dr. G. S. Groenewold, Idaho National Engineering Laboratory, P.O. Box 1625, Idaho Falls, ID 83415-2208. salts from nitric acid solutions [1]. TBP evolved as the most attractive chemical for these processes because the phosphoryl moiety coordinates with metals that have oxidation states of III or higher to form adducts or solvates [an example of such a species is $\mathrm{UO}_{2}\left(\mathrm{NO}_{3}\right)_{2}$ -2TBP]. These species are partitioned from concentrated $\mathrm{HNO}_{3}$ solutions into organic phases, and this phenomenon is exploited in separation processes [1]. Poor disposal practices for process wastes have resulted in TBP and radionuclides being buried together in uncontained landfills; as a result, TBP is a significant environmental contaminant at some Department of Energy (DOE) sites [2].

SIMS investigations of TBP have focused on basalt because it is the predominant mineral found on the DOE Hanford site [3] and at the DOE's Idaho National Engineering Laboratory (INEL). Significant nuclear fuel reprocessing and waste disposal activities have occurred at both sites, and improper disposal at Hanford has resulted in the release of TBP, radionuclides, and other contaminants into the environment [2]. Thus basalt is an environmental medium that will have to be reckoned with during the course of characterization and remediation activities. At the present time, there are no rapid means for the analysis of TBP on basalt, and little is known about the interaction of TBP with basalt surfaces. This is partly due to the fact that basalt is an inhomogeneous mineral that consists of many phases [4] and can have a highly variable surface morphology. The inhomogeneity and morphology makes contaminant-surface interactions difficult to sort out. 
In the present study, SIMS was used for the analysis of TBP on basalt because the technique is sensitive for surface contaminants and can be performed with little or no sample preparation [5,6]. As a result, many samples could be analyzed rapidly for TBP, which allowed the SIMS spectra of TBP to be correlated with the mineral phase.

\section{Experimental}

\section{Secondary Ionization Mass \\ Spectrometry Instrumentation}

The instrument used for the majority of the studies has been described in detail previously [7]; a brief description will be provided here. The instrument uses $\mathrm{ReO}_{4}^{-}$ as the primary bombarding particle, which is produced by heating a $\mathrm{Ba}\left(\mathrm{ReO}_{4}\right)_{2}$ ceramic in vacuum [8]. The ceramic was synthesized in our laboratories and processed in a form that could be used as an ion source. $\mathrm{ReO}_{4}^{-}$ions that are emitted upon heating are accelerated to $10 \mathrm{keV}$. The ion gun was typically operated at $80 \mathrm{pA}$ (the ion current from the gun could be adjusted continuously by adjusting the current that passes through the heating element that supported the ceramic). The focus of the primary ion gun was adjusted so that the sample was just silhouetted on an image intensifier located behind the sample. Thus, most of the primary ion beam is directed onto the target. A typical acquisition required $168 \mathrm{~s}$ and a typical sample had an area of about $0.03 \mathrm{~cm}^{2}$; thus a normal primary ion dose was $2.8 \times 10^{12}$ ions $/ \mathrm{cm}^{2}$, which is less than the commonly accepted static SIMS limit [9].

The secondary anions and cations were extracted from the sample target region by using pulsed secondary ion extraction [7]. This technique alternately extracts anions and cations from the sample surface by alternating the polarity of the secondary ion extraction lens. This technique mitigates charge buildup on the surface of the sample and thus permits facile analysis of electrically insulating samples like basalt and quartz. The ratio of time extracting cations to time extracting anions is adjustable in this instrument, and in the case of the basalt and quartz samples, a value of 3 worked well. The total period for the pulsed extraction sequence was $120 \mathrm{~ms}$ divided as follows: cation extraction, $84 \mathrm{~ms}$; electronic settle time, $4 \mathrm{~ms}$; anion extraction, $28 \mathrm{~ms}$; electronic settle time, $4 \mathrm{~ms}$. This sequence was repeated for each 0.2-u step of the scan of the quadrupole secondary mass spectrometer, which was scanned from 10 to $310 \mathrm{u}$. The quadrupole was a $\mathrm{m} / \mathrm{z}$ 2-2000 instrument, manufactured by Extrel (Pittsburgh, PA) and modified in our laboratory. The quadrupole was tuned for unit mass resolution and optimum sensitivity for $\mathrm{m} / \mathrm{z} 81^{-}$and $198^{+}$in the SIMS spectrum of tetrahexyl ammonium bromide [10].

Several measurements were made to verify fragmentation pathways via an ion trap SIMS instrument recently constructed in the authors' laboratory [11]. A rigorous description of this instrument is beyond the scope of this paper at this date because the instrument is still undergoing substantial refinement. Briefly, an $\mathrm{ReO}_{4}^{-}$ion gun and an offset electron multiplier are located coaxially behind one endcap of a modified Finnigan ion trap mass spectrometer (Finnigan-MAT, San Jose, CA). The sample, attached to a probe, is located $3 \mathrm{~mm}$ from the opposite endcap and the $\mathrm{ReO}_{4}^{-}$ beam at $3.5 \mathrm{keV}$ is focused on the sample through the ion trap. A diagram of the instrument is found in ref. 11. Ions in the mass range of interest were collected by using filtered noise fields applied with a Teledyne system (Teledyne Electronics Technology, Mountain View, CA), and collisionally induced dissociation was performed by using a supplementary rf field on the endcaps.

\section{Precision of Secondary Ionization Mass Spectrometry Data}

Because the interpretations in this paper are based on measurement of relative abundances, a discussion of the precision of relative abundance measurements is appropriate. Duplicate analyses of the same exposed sample were not performed because the adsorbed organic compounds (including TBP) tend to slowly desorb in the vacuum system (pressure is $5 \times 10^{-7}$ to $5 \times 10^{-6}$ torr), thereby introducing a systematic variance to the measurements. Instead, analyses of several of the same sample type, exposed to TBP, were performed for comparison purposes. The abundances were normalized to $m / z 99^{+}$(the most abundant TBP-derived peak), and the resultant relative abundances from the analyses of the same sample type were averaged (Table 1) and relative standard deviations (rsd) were calculated (parenthetical values in Table 1). For most reasonably abundant ions, a rsd of $5-50 \%$ can be expected for a given abundance measurement. The expected precision becomes less (greater rsd values) for lower abundance (and generally higher mass) ions. Furthermore, relative abundance measurements are less precise for the actual basalt sample analyses, presumably because they are chemically inhomogeneous and have irregular surface morphology compared to the model iron oxide samples that were studied. Significantly, the highest rsd values were calculated for the analyses of the INEL basalt samples: this observation is consistent with the fact that the INEL basalt contained more mineral phases, which were unevenly distributed sample-to-sample.

\section{Chemical Ionization and Electron Ionization Mass Spectrometry}

Chemical ionization $\left(\mathrm{CH}_{4}\right)$ gas chromatography-mass spectrometry (GC/MS) analyses were performed via a Hewlett-Packard 5989A MS Engine interfaced to a 
Table 1. Average relative abundances of the seven most abundant cations (relative to $m / z 99+$ ) observed in SIMS spectra of TBP and tributyl phosphate on mineral surfaces"

\begin{tabular}{|c|c|c|c|c|c|c|c|c|c|c|}
\hline \multirow[b]{2}{*}{ Mass } & \multicolumn{7}{|c|}{ TBP } & \multicolumn{3}{|c|}{ Tributyl phosphite } \\
\hline & $\begin{array}{c}\text { Aqueous } \\
\text { on } \\
\text { quartic } \\
\text { rock }\end{array}$ & $\begin{array}{c}\text { Aqueous } \\
\text { on INEL } \\
\text { basalt }\end{array}$ & $\begin{array}{l}\text { Aqueous } \\
\text { on } \\
\text { Elephant } \\
\text { Mountain } \\
\text { basalt }\end{array}$ & $\begin{array}{l}\text { Aqueous } \\
\text { on } \\
\text { Blackfoot } \\
\text { River } \\
\text { basalt }\end{array}$ & $\begin{array}{c}\mathrm{CH}_{2} \mathrm{Cl}_{2} \\
\text { on } \mathrm{Fe}_{2} \mathrm{O}_{3}\end{array}$ & $\begin{array}{l}\text { Aqueous } \\
\text { on FeO }\end{array}$ & $\begin{array}{l}\mathrm{CH}_{2} \mathrm{Cl}_{2} \\
\text { on } \mathrm{FeO}\end{array}$ & $\begin{array}{c}\text { Vapor on } \\
\text { Blackfoot } \\
\text { River } \\
\text { basalt }\end{array}$ & $\begin{array}{l}\mathrm{CH}_{3} \mathrm{Cl}_{2} \\
\text { on } \mathrm{FeO}\end{array}$ & $\begin{array}{c}\text { Vapor on } \\
\mathrm{Fe}_{2} \mathrm{O}_{3}\end{array}$ \\
\hline $83^{b}$ & 48. (91) & $48 .(43)$ & $48 .(32)$ & $52 .(38)$ & 17. & 29. & $61 .(5)$ & $86 .(28)$ & $89 .(17)$ & 191. \\
\hline 99 & 100 & 100 & 100 & 100 & 100. & 100 & 100 & 100 & 100 & 100. \\
\hline 119 & $4.6(28)$ & 14. (45) & 24. (10) & $51 .(56)$ & 3.5 & 9.3 & $45 .(11)$ & $32 .(2.1)$ & 53. (32) & 40. \\
\hline 125 & $9.2(14)$ & 13. (23) & 11. (6.9) & 14. (20) & 6.4 & 7.5 & 22. (16) & $25 .(17)$ & 19. (32) & 14. \\
\hline 137 & $5.0(6.6)$ & 16. $(60)$ & $32 .(33)$ & 48. (31) & 2.5 & 6.2 & 44. (11) & 44. (14) & 69. (24) & 73. \\
\hline 153 & $3.0(15)$ & $4.5(32)$ & $8.0(11)$ & $5.7(52)$ & 19. & 21. & 18. (24) & 12. (16) & 34. (17) & 35. \\
\hline 175 & $0.26(140)$ & $2.6(160)$ & $4.3(35)$ & 18. $(110)$ & 0.49 & 1.8 & $4.0(75)$ & $7.0(7.0)$ & $20 .(33)$ & 6.0 \\
\hline 193 & $1.3(55)$ & $2.9(116)$ & $6.2(16)$ & $9.1(26)$ & 0.78 & 8.1 & 19. (34) & $9.3(28)$ & $22 .(17)$ & 8.2 \\
\hline $\begin{array}{l}\text { \# of } \\
\text { spectra }\end{array}$ & 3 & 15 & 4 & 6 & 2 & 1 & 3 & 3 & 4 & 2 \\
\hline
\end{tabular}

aelative abundance values reported are averages of several spectra collected for separate samples exposed to TBP [except TBP (aqueous) on $\mathrm{FeO}$ ]. The number of samples analyzed/spectra collected is given in the last row. Relative standard deviation (rsd) values are given in parentheses (no rsd values were calculated for systems in which only 1 or 2 measurements were made).

${ }^{b} \mathrm{~m} / \mathrm{z}^{+} 3^{+}$is isobaric with a background $\mathrm{C}_{6} \mathrm{H}_{11}$, which arises from ubiquitous hydrocarbon background, and the cyclohexyl amine surface contaminant.

Hewlett Packard 5890 Series II gas chromatograph (Hewlett-Packard, Avondale, PA). For the chemical ionization $(\mathrm{CI})$ experiments, the reagent gas pressure in the ion source was adjusted such that the abundance of $m / z 41^{+}$was optimized, and this corresponded to an ion gauge reading of $2 \times 10^{-+}$torr on the ion gauge located on the source manifold; the source pressure was estimated to be 3 orders of magnitude higher. Electron ionization (EI) mass spectra were acquired via a Varian Saturn ITMS (ion trap); electron energy was $70 \mathrm{eV}$.

\section{Scanning Electron Microscope and Energy Disperse $X$-Ray Spectroscopy}

The mineral compositions of the basalt samples were investigated by using scanning electron microscopy (SEM) and energy dispersive $x$-ray spectroscopy (EDS). No attempt was made to cut or polish the basalt chips prior to SEM and EDS (or SIMS) analysis. This decision was made to ensure that the sample surfaces would be undisturbed and would hence correlate well with the types of basalt chips that would be encountered in the field. A consequence of this decision is that the error in the EDS data may be augmented because the surface is not flat. However, the samples were mounted to provide relatively flat areas for analysis and minimize this error. SEM images were obtained by using an Amray Model 1830 instrument (Bedford, MA), which was operated with a $20-\mathrm{keV}$ electron beam. EDS analyses were performed by using a Fisons-Kevex Delta 5 instrument (San Carlos, CA). As in the case of the SEM analyses, $20-\mathrm{keV}$ incident electrons were used. The spatial resolution for this analysis is approximately
1-2 $\mu \mathrm{m}$, which corresponds to the diameter of the approximate volume excited by the incident electron beam. The EDS analyses were standardless, and ZAF ( $Z$ number, absorption, fluorescence) corrections were accomplished by using either the Magic $V$ or extended PHIRHOZ (XPP, Quantex + version 6 software; Fisons Instrument Manufacturers, Inc., San Carlos, CA) quantification routines. Magic V [12] was used when oxygen was not present in the spectrum, and XPP, which is considered more accurate for light elements, was used when oxygen was present. For elements that are $>5$ atom $\%$, the accuracy of this method is on the order of $4-8 \%$ (relative) when analyzing flat, polished specimens.

\section{Sample Origin and Handling and Preparation}

Basalt samples were collected from the Central Facilities Area of the INEL, the Blackfoot River area of southeast Idaho, and the Elephant Mountain area, near the Hanford reservation (Washington). The INEL basalt was chosen because it is typical of the INEL site: it has a very rough surface morphology that is typical of young basalt (in this case approximately 7000 years old). The Blackfoot River basalt that was collected from off the INEL site had a smoother surface as a result of extensive weathering. This basalt is older than the INEL basalt, but the exact age is not known. The Elephant Mountain basalt is also smoother and older (it is thought to be approximately 10.5 million years old) and is typical of the Hanford site [3]. One additional sample was analyzed: a quartzic rock collected from the Raritan, NJ area. Samples from this area are being studied because it has experienced environmental contamination from chemical warfare agents. The 
Raritan rocks consisted almost entirely of $\mathrm{SiO}_{2}$ (as determined by EDS).

Typical sample preparation involved wrapping the basalt or quartz sample in a paper towel and then pounding it with a hammer to make small rock chips (size was variable, but typically $2 \mathrm{~mm}$ in diameter). These chips were then attached to target planchets with double-sided tape and admitted to the spectrometer by using a direct insertion probe.

The basalt and quartz chips and the ferrous and ferric oxide powders were exposed to TBP in three different ways:

1. Known quantities of aqueous TBP solutions were spiked onto the mineral surfaces and allowed to dry prior to admitting the samples into the instrument.

2. The mineral samples were immersed in aqueous or $\mathrm{CH}_{2} \mathrm{Cl}_{2}$ solutions of TBP for typically $1-2 \mathrm{~h}$, removed, and allowed to dry.

3. Samples were exposed to TBP in the atmosphere by holding a basalt sample over an open bottle of TBP for 15 to $60 \mathrm{~s}$.

The concentrations of the TBP $/ \mathrm{H}_{2} \mathrm{O}$ and TBP $/ \mathrm{CH}_{2} \mathrm{Cl}_{2}$ solutions were 800 and $1000 \mathrm{ppm}$, respectively. All TBP exposures were conducted at room temperature. These concentrations resulted in SIMS spectra that had good signal-to-background, whether the samples were spiked or immersed in the TBP solutions.

Samples were exposed to tributyl phosphite in two ways:

1. Chips were suspended for $1-2 \mathrm{~h}$ in a vial that contained a few microliters of tributyl phosphite in the bottom.

2. Chips were spiked with 2-4 $\mu \mathrm{L}$ of tributyl phosphite $/ \mathrm{CH}_{2} \mathrm{Cl}_{2}$ solution $(1 \mu \mathrm{g} / \mu \mathrm{L})$.

Similar spectra (ions and relative abundances) were observed with both techniques. All tributyl phosphite exposures were conducted at room temperature.

\section{Chemicals}

Tributyl phosphate was obtained from MCB Manufacturing Chemists, Inc. (Cincinnati, $\mathrm{OH}$ ). The purity of TBP was checked via GC/MS; only TBP was observed in the chromatogram. Tributyl phosphite (technical grade) was obtained from Aldrich Chemical Co. (Milwaukee, WI); GC/MS analysis of this compound showed an impurity that was identified as tributyl phosphate. The concentration of tributyl phosphate in the tributyl phosphite was estimated at 3-4\%, based on the GC/MS peak areas. Iron(III) oxide was obtained from John Mathey Specialty Products (Danvers, MA), and was grade I. Iron(II) oxide was obtained from Cerac (Milwaukee, WI).

\section{Results}

Secondary Ionization Mass Spectrometry Analysis of Tri-n-butyl Phosphate on Basalt, Quartz, and Iron Oxides

The cation SIMS spectra of basalt samples from three different geographical locations and of quartz samples were similar in that they contained peaks that corresponded to even-electron hydrocarbon ions, alkali metal ions, and ions derived from phthalate and siloxane (Figure 1a). In addition, ions that originated from cyclohexylamine were usually observed: this compound is added to the laboratory boiler at INEL to prevent scaling, and gets into the laboratory air because the boiler also is used for humidification. These observations are consistent with the idea that most of the secondary ion signal originates from surface contaminants. Fortunately, few ions above mass 100 were very abundant in the spectra of the unexposed samples, which allowed the chemistry of TBP to be observed without significant isobaric interferences.

Ions that originate from TBP could be observed readily in the cation SIMS spectra of basalt, quartz, and iron oxide samples that had been exposed to TBP (Figure $1 \mathrm{~b}$ and $\mathrm{c}$ and Table 1). These ions could be observed when the samples were exposed to TBP solutions $\left(\mathrm{H}_{2} \mathrm{O}\right.$ or $\left.\mathrm{CH}_{2} \mathrm{Cl}_{2}\right)$ or TBP vapor. On a qualitative basis, the SIMS spectra of TBP were consistent irrespective of the method of exposure for all surfaces, except $\mathrm{FeO}$ (see succeeding text). The fact that TBP vapor readily would contaminate a mineral surface created problems in the laboratory, because when neat TBP or highly TBP-contaminated samples were manipulated in the lab, it was subsequently difficult to acquire a SIMS spectrum of basalt that did not have ions derived from TBP. The phenomenon is indicative of both the unusual ability of TBP to adsorb to mineral surfaces and the high sensitivity of SIMS for the detection of surface-adsorbed compounds. A positive aspect of the phenomenon is that it provided a means by which mineral samples could be exposed to TBP without the use of solvent.

The relative abundances of the salient ions observed in the cation SIMS spectra of TBP were observed to vary significantly, dependent on the mineral sample (Table 1). Changes in the abundances of ions at $\mathrm{m} / \mathrm{z}$ $193^{+}, 175^{+}, 137^{+}$, and $119^{+}$permit the samples to be grouped into two categories: abundances of these ions are highest in the spectra of Elephant Mountain (Figure $1 \mathrm{~b}$ ) and Blackfoot River basalts and $\mathrm{FeO}$ (exposed to $\mathrm{TBP} / \mathrm{CH}_{2} \mathrm{Cl}_{2}$ solution), and significantly lower in the spectra of the INEL basalt (Figure 1c), Raritan quartz, and $\mathrm{Fe}_{2} \mathrm{O}_{3}$. A second distinction may be made based on the abundance of $\mathrm{m} / z 153^{+}$, which is high in the case of the iron oxides, but lower for the other four samples.

The cation SIMS spectrum of TBP on $\mathrm{FeO}$ was varied dependent on the method of exposure: when 
a

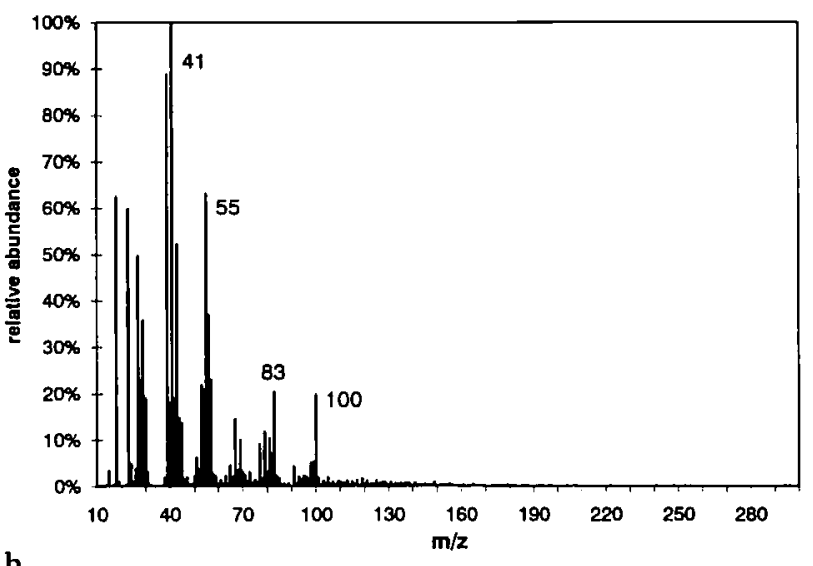

b
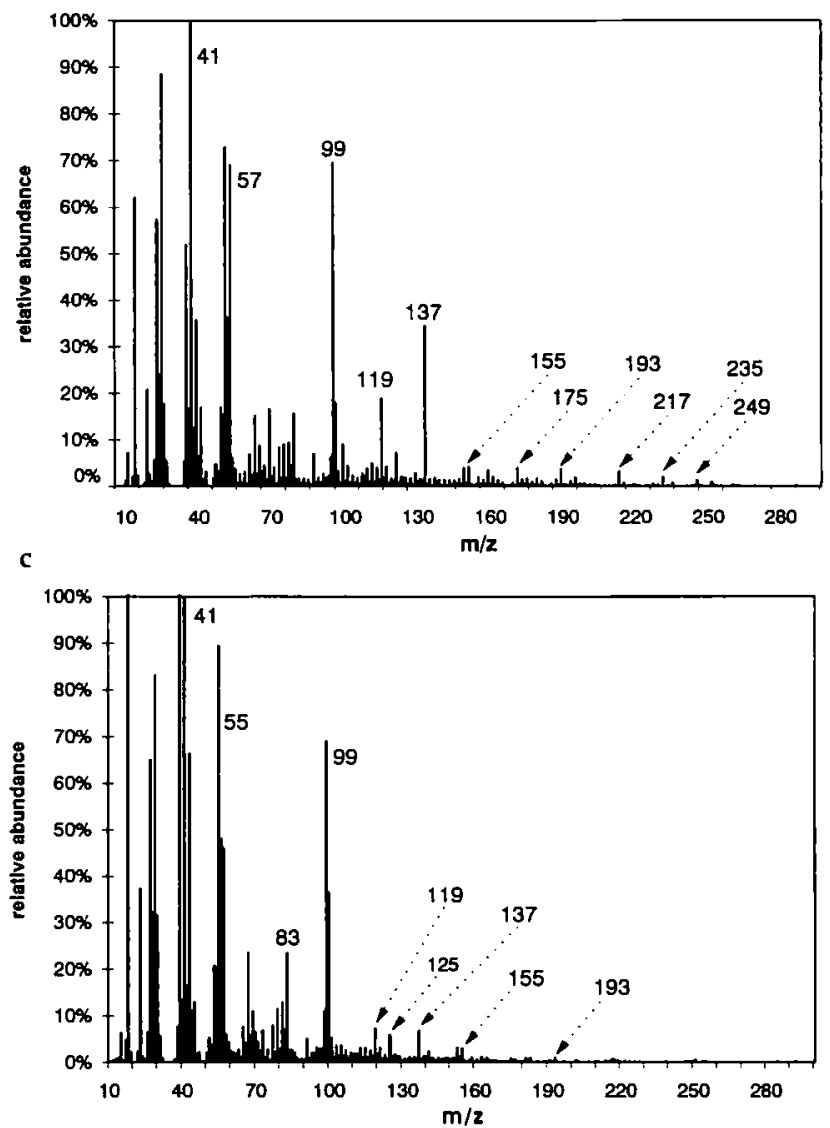

Figure 1. Cation SIMS spectra of three basalt samples. (a) INEL basalt, unexposed to TBP. The spectra of unexposed basalt and quartz samples are very similar to this spectrum. (b) Elephant Mountain basalt, exposed to $1-\mu \mathrm{g} / \mu \mathrm{L} \mathrm{TBP} / \mathrm{H}_{2} \mathrm{O}$. (c) INEL basalt, exposed to $1-\mu \mathrm{g} / \mu \mathrm{L}$ TBP $/ \mathrm{H}_{2} \mathrm{O}$. The spectra presented are individual analyses, which are representative of the sample types specified. Consequently, the spectra are not in indentical agreement with the averaged data presented in Table 1.

$\mathrm{FeO}$ was exposed to TBP vapor or TBP $/ \mathrm{CH}_{2} \mathrm{Cl}_{2}$ solutions, the SIMS spectrum appeared very much like the Elephant Mountain and Blackfoot River basalt samples. When $\mathrm{FeO}$ was exposed to aqueous TBP, on the other hand, the spectrum looked like the spectrum collected from the $\mathrm{Fe}_{2} \mathrm{O}_{3}$ sample; in fact, tiny patches of orange, oxidized $\mathrm{FeO}$ could be observed (via an optical microscope) on the sample that had been exposed to the aqueous TBP solution.

\section{Scanning Electron Microscope /Energy Dispersive $X$-Ray Spectroscopy Analyses of Basalt}

The surfaces of the basalt samples were difficult to quantitatively describe because they were very inhomogeneous (Figure 2): scanning electron micrographs together with energy dispersive $\mathrm{x}$-ray spectroscopy (EDS) revealed that samples from all three locations contained four general types of mineral phases: plagioclase, pyroxene, olivine, and Ti-bearing spinels. Plagioclase accounts for the largest fraction of the surface area of the basalt samples that were studied, and by definition, its composition ranges from anorthite $\left(\mathrm{CaAl}_{2} \mathrm{Si}_{2} \mathrm{O}_{8}\right)$ to albite $\left(\mathrm{NaAlSi}{ }_{3} \mathrm{O}_{8}\right)$. Generally, plagioclase contains little $\mathrm{Fe}$ and appears as dark gray to black areas in the backscattered electron images generated by the SEM (indicative of few higher $Z$ number elements; see Figure 2). Pyroxene phases also were observed on the sample surfaces; in contrast to the plagioclase, the pyroxenes contained substantial amounts of Fe. By definition, pyroxenes have the stoichiometry $\mathrm{X}_{1-p} \mathrm{Y}_{1+p} \mathrm{Si}_{2} \mathrm{O}_{6}$, where $\mathrm{X}$ is $\mathrm{Ca}$ or $\mathrm{Na}$ and $\mathrm{Y}$ can be Fe (in the +2 or +3 oxidation states) or other metals, and $0 \leq p \leq 1$. Olivine phases also were observed in most of the samples, although in general they are not as prevalent as are the plagioclase and pyroxene phases. The olivines have the general formula $\mathrm{Mg}_{x} \mathrm{Fe}_{2-x} \mathrm{SiO}_{4}$, where $0 \leq x \leq 2$. Finally, most of the samples that were examined had smaller areas

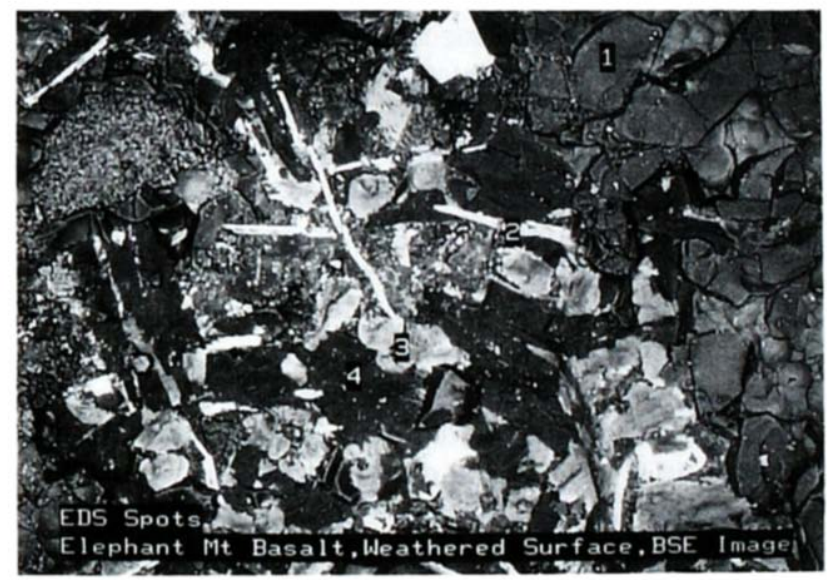

Figure 2. Typical electron backscattered scanning electron micrograph of an unpolished basalt chip from the Elephant Mountain formation, Hanford, Washington. The surface is very heterogeneous and contains phases that have $\mathrm{Fe}(\mathrm{II})$, which is responsible for the observation of "reduced" TBP ions in the SIM spectra. Spots 1 and 3 are pyroxene phases that contain 7-9-atom \% Fe; Fe can be in the +2 or +3 oxidation states in these phases. Spot 1 contained a small amount of $\mathrm{Al}$, whereas spot 3 contained a substantial amount of $\mathrm{Mg}$. Spot 2 is ilmenite $\left(\mathrm{FeTiO}_{3}\right.$ ), where $\mathrm{Fe}$ is in the +2 oxidation state. Spot 4 is a plagioclase phase that has $13 \% \mathrm{Al}$ and no $\mathrm{Fe}$. 
that corresponded to phases that were high in $\mathrm{Ti}$ : examples of these minerals are ilmenite, $\mathrm{FeTiO}_{3}$, and ulvospinel, $\mathrm{Fe}_{2} \mathrm{TiSiO}_{4}$. These Ti-bearing spinels are observed readily as bright areas in the backscattered electron images generated by the SEM (Figure 2). The important observation relative to the SIMS behavior of TBP on basalt is the fact that substantial amounts of $\mathrm{Fe}^{+2}$ are certainly present in the olivine and Ti-spinel phases, and probably in the pyroxenes.

When the SEM/EDS analyses of basalt samples from different areas were compared, significant qualitative differences were observed. Plagioclase was the most important phase in the samples of INEL basalt; it accounts for up to $90 \%$ of the surface area (based on visual estimation). A minor phase was identified as Fe-bearing pyroxene. Occasionally, samples of INEL basalt contained higher percentages of Fe-bearing phases, which were identified as hematite $\left(\mathrm{Fe}_{2} \mathrm{O}_{3}\right)$. This identification was consistent with the reddish color of these samples. No olivine phases were observed, and Ti-bearing spinels accounted for only a small fraction of the total surface area. Significantly, phases that contain Fe(II) are much less prevalent in INEL basalts than in the Elephant Mountain or Blackfoot River samples.

Although the Elephant Mountain basalt samples also contained substantial plagioclase phases, they could be distinguished readily from the INEL basalt samples by the presence of Ti-bearing spinels and olivine phases, which accounted for a significant portion of the surface area. These phases all contain substantial amounts of $\mathrm{Fe}(\mathrm{II})$. Specific phases identified included fayalite $\left(\mathrm{Fe}_{2} \mathrm{SiO}_{4}\right.$, an olivine), ilmenite $\left.(\mathrm{FeTiO})_{3}\right)$, and ulvospinel $\left(\mathrm{Fe}_{2} \mathrm{TiO}_{4}\right)$. In addition, pyroxene phases that contained substantial Fe (7-10 atom $\%$ ) were more abundant than in the case of the INEL basalt samples.

Fewer phases were observed in the SEM/EDS images of the Blackfoot River basalt. As in the cases of the Elephant Mountain and INEL basalts, plagioclase accounted for substantial fractions of the sample surfaces $(70-80 \%$, based on visual estimation), but large areas of olivine $\left(\mathrm{FeMgSiO}_{4}\right)$ and ulvospinel $\left(\mathrm{Fe}_{2} \mathrm{TiO}_{4}\right)$ phases occupied most of the rest of the surface (surface coverage of up to $10 \%$ for each phase). The presence of $\mathrm{Fe}$ (II) in these phases distinguishes them from the INEL basalt samples.

A quartzic rock obtained from a Raritan, NJ site was analyzed for comparison with the basalt. SEM/EDS analyses revealed that the sample was overwhelmingly $\mathrm{SiO}_{2}$, with a few very small areas that contained transition metals.

\section{Secondary Ionization Mass Spectrometry Analysis of Tributyl Phosphite on Basalt, Quartz, and Iron Oxides}

When Blackfoot River basalt was exposed to tributyl phosphite vapor, the same set of secondary ions was observed as in the case of TBP (Table 1), together with a $m / z 83^{+}$, which was more abundant than in the background spectra or the TBP-exposed spectra. The absolute abundances (counts per second) of the secondary ions for tributyl phosphite were usually on the order of 2-5 times lower than similar TBP ion abundances for similar samples exposed in the same fashion. This may indicate that more TBP is adsorbed to the sample surface or that TBP is more prolific at cation formation than tributyl phosphite. The relative abundances of the tributyl phosphite ions observed on Blackfoot River basalt were in reasonable agreement with those recorded for TBP on Blackfoot River and Elephant Mountain basalts and on $\mathrm{FeO}$ (the latter exposed to gas-phase TBP).

The analysis of tributyl phosphite on $\mathrm{FeO}$ (deposited as a $\mathrm{CH}_{2} \mathrm{Cl}_{2}$ solution, 1 part per thousand) was difficult to interpret because the intensity of the tributyl phosphite ions sputtered from $\mathrm{FeO}$ was lower than from other samples. Nevertheless, $m / z 193^{+}$, $175^{+}, 153^{+}, 137^{+}, 119^{+}, 99^{+}$, and $83^{+}$were clearly discernible above the background. The $\mathrm{FeO}$ powder also was exposed to tributyl phosphite vapor; in this experiment, the same ions were observed, but the absolute ion abundances were less than in the $\mathrm{CH}_{2} \mathrm{Cl}_{2}$ experiment. In both the tributyl phosphite on $\mathrm{FeO}$ experiments (vapor and $\mathrm{CH}_{2} \mathrm{Cl}_{2}$ solution exposures), the relative abundances of these ions were similar to tributyl phosphite on Blackfoot River basalt and to TBP on FeO, Blackfoot River basalt, and Elephant Mountain basalt. For example, $m / z 137^{+}$was observed at 40 to $70 \%$ in the tributyl phosphite spectra, which suggests that the tributyl phosphite spectra can be grouped with the spectra of TBP on Fe(II)-bearing basalts and on $\mathrm{FeO}$.

The SIMS spectrum of tributyl phosphite (gas phase) on $\mathrm{Fe}_{2} \mathrm{O}_{3}$ is very similar to that obtained for $\mathrm{FeO}$.

\section{Gas-Phase Behavior of Ionized Tri-n-butyl Phosphate and Tributyl Phosphite}

The chemical ionization (CI) and electron ionization (El) mass spectra of the subject compounds were examined to determine whether the ions attributed to surface reduction also could be formed from gas-phase processes. The methane $\mathrm{CI}$ spectrum (Table 2) of TBP consists nearly entirely of $\left[\mathrm{M}+\mathrm{C}_{3} \mathrm{H}_{5}\right]^{+},[\mathrm{M}+$ $\left.\mathrm{C}_{2} \mathrm{H}_{5}\right]^{+},[\mathrm{M}+\mathrm{H}]^{+}$, and $[\mathrm{M}-\mathrm{H}]^{+}$and the elimination of up to three butene molecules from these molecular species. The elimination of butene molecule(s) has been verified in our laboratory by using a new ion trap SIMS instrument recently constructed in the authors' laboratory: $m / z 267^{+}$produces $211^{+}, 155^{+}$, and $99^{+}$; $211^{+}$produces $155^{+}$and $99^{+} ; 155^{+}$produces $99^{+}$; $137^{+}$produces $119^{+}$.

The EI mass spectrum of TBP [13] (Table 3) contains a low abundance $\mathrm{M}^{+}$at $m / z 266^{+}$, which fragment via the loss of a $\mathrm{C}_{4} \mathrm{H}_{7}$ radical $\left(\mathrm{m} / z 211^{+}\right)$, and then 
Table 2. Methane $\mathrm{CI}$ mass spectra of TBP and tributyl phosphite

\begin{tabular}{|c|c|c|c|c|}
\hline \multirow[b]{2}{*}{ Assignment } & \multicolumn{2}{|c|}{ TBP } & \multicolumn{2}{|c|}{$\begin{array}{c}\text { Tributyl } \\
\text { phosphite }\end{array}$} \\
\hline & $m / z$ & r.a. $^{a}$ & $m / z$ & r.a. $^{a}$ \\
\hline $\mathrm{C}_{4} \mathrm{H}_{7}^{+}$ & 57 & 26. & 57 & 74. \\
\hline$\left[M+H^{+}-3 C_{4} H_{8}\right]$ & 99 & 17. & 83 & 100. \\
\hline Unknown & & & 97 & 2.2 \\
\hline $\begin{array}{l}\text { Possibly }\left[\mathrm{M}+\mathrm{H}^{+}-\mathrm{C}_{2} \mathrm{H}_{6}\right. \\
\left.\quad-2 \mathrm{C}_{4} \mathrm{H}_{8}\right]\end{array}$ & 125 & 1.2 & & \\
\hline$\left[\mathrm{M}+\mathrm{C}_{2} \mathrm{H}_{5}^{+}-3 \mathrm{C}_{4} \mathrm{H}_{8}\right]$ & 127 & 1.2 & 111 & 17. \\
\hline$\left[\mathrm{M}+\mathrm{C}_{3} \mathrm{H}_{5}^{+}-3 \mathrm{C}_{4} \mathrm{H}_{8}\right]$ & 139 & 1.2 & 123 & 4.7 \\
\hline$\left[\mathrm{M}-\mathrm{H}^{+}-2 \mathrm{C}_{4} \mathrm{H}_{8}\right]$ & 153 & 1.0 & 137 & 4.0 \\
\hline$\left[\mathrm{M}+\mathrm{H}^{+}-2 \mathrm{C}_{4} \mathrm{H}_{8}\right]$ & 155 & 19. & 139 & 59. \\
\hline$\left[\mathrm{M}+\mathrm{C}_{2} \mathrm{H}_{5}^{+}-2 \mathrm{C}_{4} \mathrm{H}_{8}\right]$ & 183 & 2.1 & 167 & 14. \\
\hline$\left[\mathrm{M}+\mathrm{C}_{3} \mathrm{H}_{5}^{+}-2 \mathrm{C}_{4} \mathrm{H}_{8}\right]$ & 195 & 2.1 & 179 & 1.9 \\
\hline$\left[\mathrm{M}-\mathrm{H}^{+}-\mathrm{C}_{4} \mathrm{H}_{8}\right]$ & 209 & 1.8 & 193 & 1.6 \\
\hline$\left[\mathrm{M}+\mathrm{H}^{+}-\mathrm{C}_{4} \mathrm{H}_{8}\right]$ & 211 & 54. & 195 & 59. \\
\hline Possibly $\left[\mathrm{M}+\mathrm{H}^{+}-\mathrm{C}_{3} \mathrm{H}_{8}\right]$ & 223 & 3.1 & & \\
\hline$\left[\mathrm{M}+\mathrm{C}_{2} \mathrm{H}_{5}^{+}-\mathrm{C}_{4} \mathrm{H}_{8}\right]$ & 239 & 9.3 & 223 & 4.6 \\
\hline$\left[\mathrm{M}+\mathrm{C}_{3} \mathrm{H}_{5}^{+}-\mathrm{C}_{4} \mathrm{H}_{8}\right]$ & 251 & 3.9 & 235 & 5.1 \\
\hline$\left[\mathrm{M}-\mathrm{H}^{+}\right]$ & 265 & 9.9 & 249 & 0.1 \\
\hline$\left[M+H^{+}\right]$ & 267 & 100. & 251 & $<0.1$ \\
\hline$\left[\mathrm{M}+\mathrm{C}_{2} \mathrm{H}_{5}^{+}\right]$ & 295 & 17. & 279 & 0.0 \\
\hline$\left[\mathrm{M}+\mathrm{C}_{3} \mathrm{H}_{5}^{+}\right]$ & 307 & 7.1 & 291 & 0.0 \\
\hline
\end{tabular}

${ }^{a}$ r.a. $=$ abundance relative to the base peak.

undergoes losses of $\mathrm{C}_{4} \mathrm{H}_{8}$, to produce ions at $155^{+}$and $99^{+}[14]$.

The CI mass spectra of tributyl phosphite (Table 2) was dominated by the sequential losses of three $\mathrm{C}_{4} \mathrm{H}_{8}$ molecules from a very low abundance $[\mathrm{M}+\mathrm{H}]^{+}(\mathrm{m} / \mathrm{z}$ $251^{+}$) to form $m / z 195^{+}, 139^{+}$, and $83^{+}$(base peak). A lower abundance ion series was observed at $m / z 249^{+}$, $193^{+}$, and $137^{+}$: the observation of these ions is noted for comparison with the SIMS spectra, where they are substantially more abundant.

The fragmentation reactions of tributyl phosphite under EI conditions [13] (Table 3) were very similar to the El fragmentations of TBP: the very low abundance $\mathrm{M}^{+}$eliminates a $\mathrm{C}_{4} \mathrm{H}_{7}$ radical to form $\mathrm{m} / \mathrm{z} 195^{+}$, which subsequently undergoes sequential losses of $\mathrm{C}_{4} \mathrm{H}_{8}$, to produce ions at $139^{+}$and $83^{+} . \mathrm{m} / \mathrm{z} 195^{+}$also can eliminate $\mathrm{H}_{2} \mathrm{O}$ to form $\mathrm{m} / z 177^{+}$, which further undergoes losses of two $\mathrm{C}_{4} \mathrm{H}_{8}$ to form $\mathrm{m} / z \mathrm{z}^{+} 1^{+}$and $65^{+} . \mathrm{m} / \mathrm{z} 83^{+}$accounts for the base peak in the spectrum.

\section{Discussion}

\section{Production of $m / z 137^{+}$and Related lons}

The observation of abundant ions at $\mathrm{m} / z 137^{+}$and $119^{+}$(as well as less abundant ions at $m / z 249^{+}, 193^{+}$, and $175^{+}$) in the SIMS spectra of TBP on FeO, but not
Table 3. EI mass spectra of TBP and tributyl phosphite [13]

\begin{tabular}{|c|c|c|c|c|}
\hline \multirow[b]{2}{*}{ Assignment } & \multicolumn{2}{|c|}{ TBP } & \multicolumn{2}{|c|}{ tributyl phosphite } \\
\hline & $m / z$ & r.a. ${ }^{a}$ & $m / z$ & r.a. ${ }^{a}$ \\
\hline $\mathrm{C}_{4} \mathrm{H}_{7}^{+}$ & 57 & 15 & 57 & 29 \\
\hline $\begin{array}{c}{\left[\mathrm{M}-\mathrm{C}_{4} \mathrm{H}_{7}-2 \mathrm{C}_{4} \mathrm{H}_{8}\right.} \\
\left.-\mathrm{H}_{2} \mathrm{O}^{+}\right]\end{array}$ & 81 & 2.4 & 65 & 4.2 \\
\hline$\left[\mathrm{M}-\mathrm{C}_{4} \mathrm{H}_{7}-2 \mathrm{C}_{4} \mathrm{H}_{8}^{+}\right]$ & 99 & 100 & 83 & 100 \\
\hline$\left[\mathrm{M}-\mathrm{C}_{3} \mathrm{H}_{7}-2 \mathrm{C}_{4} \mathrm{H}_{8}^{+}\right]$ & 111 & 4.5 & & \\
\hline$\left[\mathrm{M}-\mathrm{C}_{2} \mathrm{H}_{5}-2 \mathrm{C}_{4} \mathrm{H}_{8}^{+}\right]$ & 125 & 8.6 & & \\
\hline $\begin{array}{c}{\left[\mathrm{M}-\mathrm{C}_{4} \mathrm{H}_{7}-\mathrm{C}_{4} \mathrm{H}_{8}\right.} \\
\left.-\mathrm{H}_{2} \mathrm{O}^{+}\right]\end{array}$ & 137 & 7.8 & 121 & 2.7 \\
\hline$\left[\mathrm{M}-\mathrm{C}_{4} \mathrm{H}_{7}-\mathrm{C}_{4} \mathrm{H}_{8}^{+}\right]$ & 155 & 32 & 139 & 17 \\
\hline$\left[\mathrm{M}-\mathrm{C}_{3} \mathrm{H}_{7}-\mathrm{C}_{4} \mathrm{H}_{8}^{+}\right]$ & 167 & 4.5 & & \\
\hline$\left[\mathrm{M}-\mathrm{C}_{4} \mathrm{H}_{7}-\mathrm{H}_{2} \mathrm{HO}^{+}\right]$ & & & 177 & 2.6 \\
\hline$\left[\mathrm{M}-\mathrm{C}_{2} \mathrm{H}_{5}-\mathrm{C}_{4} \mathrm{H}_{8}^{+}\right]$ & 181 & 2.8 & & \\
\hline$\left[\mathrm{M}-\mathrm{C}_{4} \mathrm{H}_{7}^{+}\right]$ & 211 & 30 & 195 & 4.8 \\
\hline$\left[\mathrm{M}-\mathrm{C}_{3} \mathrm{H}_{7}^{+}\right]$ & 223 & 2.8 & & \\
\hline$\left[\mathrm{M}-\mathrm{C}_{2} \mathrm{H}_{5}^{+}\right]$ & 237 & 2.4 & & \\
\hline$\left[\mathrm{M}^{+}\right]$ & 266 & 2.4 & 250 & 0.2 \\
\hline
\end{tabular}

$\mathrm{Fe}_{2} \mathrm{O}_{3}$ or quartz, indicates that $\mathrm{Fe}$ (II) on the surface is necessary for their observation. This conclusion is consistent with the data obtained for the basalt samples: abundant "Fe(II)-induced" ions (i.e., $m / z \quad 137^{+}$and $119^{+}$) were observed in the spectra of the TBP-exposed Elephant Mountain and Blackfoot River basalt samples, whereas abundances were significantly lower for the INEL basalt and practically indistinguishable from background for the quartz. The spectral differences observed when the basalt samples were compared is attributed to the presence of substantial Fe(II)-bearing phases in the Elephant Mountain and Blackfoot River samples. These ions are interpreted in terms of concomitant reduction and hydride abstraction that occur upon ion bombardment (Figure 3), followed by loss of one or two butenes or butanols.

Gas-phase production of $\mathrm{m} / z 137^{+}$and so forth from ionized TBP is not likely. The methane CI mass spectrum shows that gas-phase TBP undergoes protonation and hydride abstraction (as it does on surfaces) and that these processes are followed by one, two, and or three $\mathrm{C}_{4} \mathrm{H}_{8}$ eliminations. However, TBP has no propensity for the formation of $m / z 137^{+}$[or the other $\mathrm{Fe}(\mathrm{II})$ ions mentioned] under $\mathrm{CI}$ conditions, which further supports the contention that these ions are the result of surface chemistry.

Because much of the discussion is based on the $\mathrm{m} / \mathrm{z}$ $137^{+}$, it must be noted that a low abundance $m / z 137^{+}$ ion $(\sim 8 \%)$ is observable in the EI mass spectrum of TBP (Table 3). Hence one explanation for the observation of this ion in the SIMS spectra would be a one electron oxidation of TBP followed by elimination reactions to form $m / z 137^{+}$. Reasonable elimination reactions would be loss of a $\mathrm{C}_{4} \mathrm{H}_{7}$ radical followed by the loss of $\mathrm{C}_{4} \mathrm{H}_{9} \mathrm{OH}$ or $\left(\mathrm{C}_{4} \mathrm{H}_{8}+\mathrm{H}_{2} \mathrm{O}\right)$. This explana- 


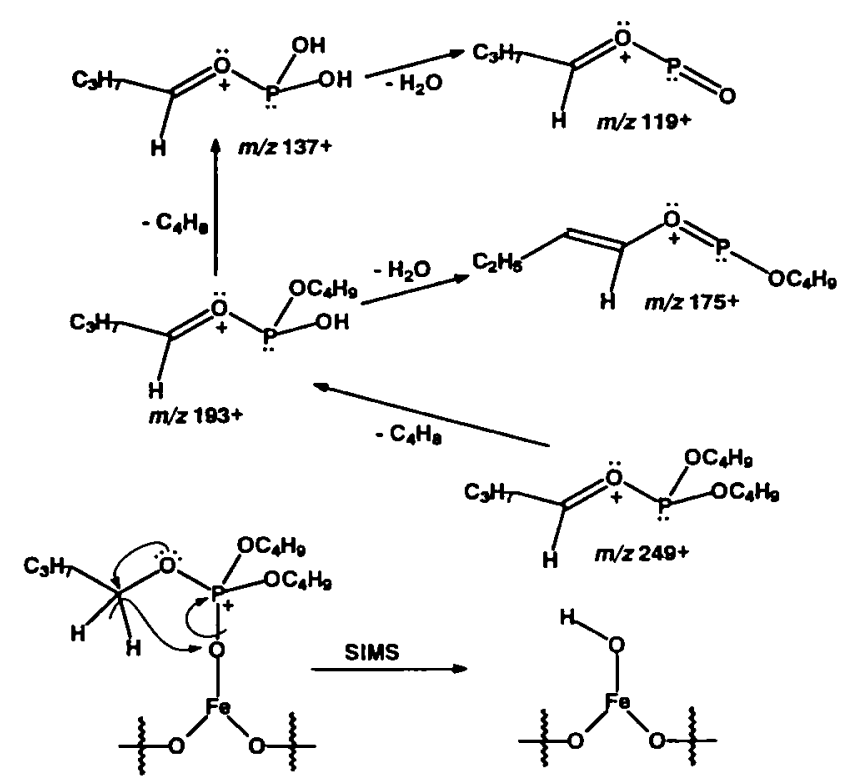

Figure 3. Mechanism proposed for the formation of $m / z 137^{+}$ in the SIM spectrum of TBP adsorbed to Fe(II)-bearing surfaces.

tion is not favored for three reasons:

1. Under SIMS conditions, radical ions (in this case, TBP radical cation) tend to be substantially less important than even electron ions.

2. This process should be observable irrespective of the mineral matrix.

3. The abundance of the $m / z 137^{+}$in the EI spectrum $(8 \%)$ is not consistent with the abundances observed in the SIMS spectra collected on reducing surfaces $(40-70 \%)$.

Thus we believe that one-electron oxidation leading to $m / z 137^{+}$is at most a minor contributor to the abundance of this ion as observed in the SIMS spectra.

\section{Production of $\mathrm{m} / \mathrm{z} 153^{+}$}

The $m / z 153^{+}$ion observed in the spectra of TBP on the iron oxide surfaces is interpreted in terms of hydride abstraction followed by the elimination of two $\mathrm{C}_{4} \mathrm{H}_{8}$ molecules. These reactions also are observed as a low abundance ion series in the methane $\mathrm{CI}$ spectrum of TBP. The elimination of a third $\mathrm{C}_{4} \mathrm{H}_{8}$ molecule to form $\mathrm{m} / \mathrm{z} 97^{+}$could occur only with difficulty, because of the formation of a $\mathrm{C}=\mathrm{O}$ bond upon hydride abstraction; in fact, only very low abundance $\mathrm{m} / \mathrm{z} 97^{+}$ ions are observed. The mechanism proposed (Figure 4) would require the presence of a $\mathrm{Fe}(\mathrm{III})$ species to accept the hydride, which is consistent with the observation of abundant $m / z 153^{+}$on $\mathrm{Fe}_{2} \mathrm{O}_{3} \cdot \mathrm{m} / z 153^{+}$is also observed in the spectrum of TBP on $\mathrm{FeO}$; we believe that this may be due to a partial layer of more highly oxidized iron oxide species on the surface of the $\mathrm{FeO}$ particles.

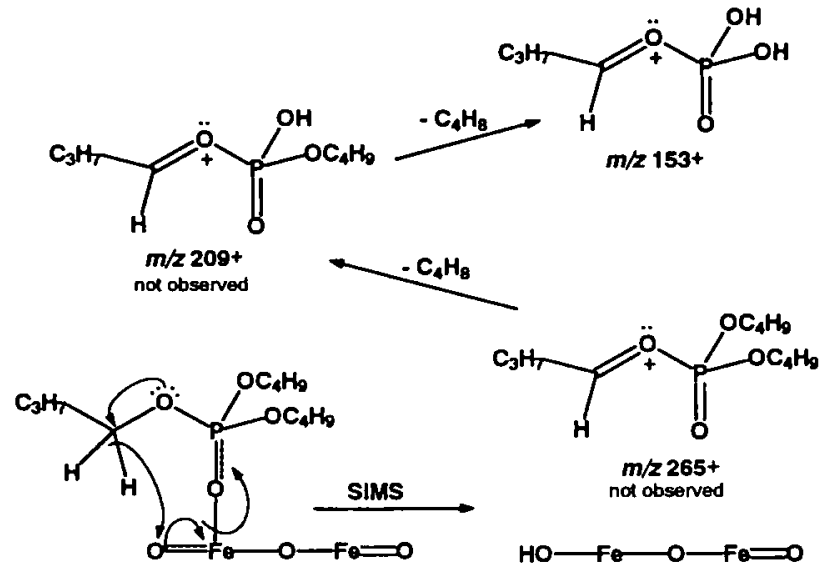

Figure 4. Proposed mechanism for surface hydride abstraction and subsequent elimination of two $\mathrm{C}_{4} \mathrm{H}_{8}$ molecules to form $\mathrm{m} / \mathrm{z}$ $153^{+}$.

\section{Production of $\mathrm{m} / \mathrm{z} 99^{+}$and $155^{+}$}

The $m / z 99^{+}$and $155^{+}$ions are formed by the protonation of TBP followed by the elimination of two and three $\mathrm{C}_{4} \mathrm{H}_{8}$ molecules (Figure 5). They are observed in all SIMS spectra of TBP presented here and are the dominant ions in the CI mass spectra of TBP. Significantly, they are much more abundant than $m / z 137^{+}$ and $153^{+}$in the SIMS spectrum of TBP on quartz (no $\mathrm{Fe}$ ), which indicates that $\mathrm{SiO}_{2}$ surfaces are efficient at protonation and reinforces the necessity for $\mathrm{Fe}$ for reduction and hydride abstraction.

SIMS ionization is substantially more energetic than methane $\mathrm{CI}$ : the base peak in the $\mathrm{CI}$ spectrum of TBP corresponds to $[\mathrm{M}+\mathrm{H}]^{+}$, which indicates that the ionization is sufficiently soft that a substantial fraction of the TBP ions formed remain intact. In contrast,

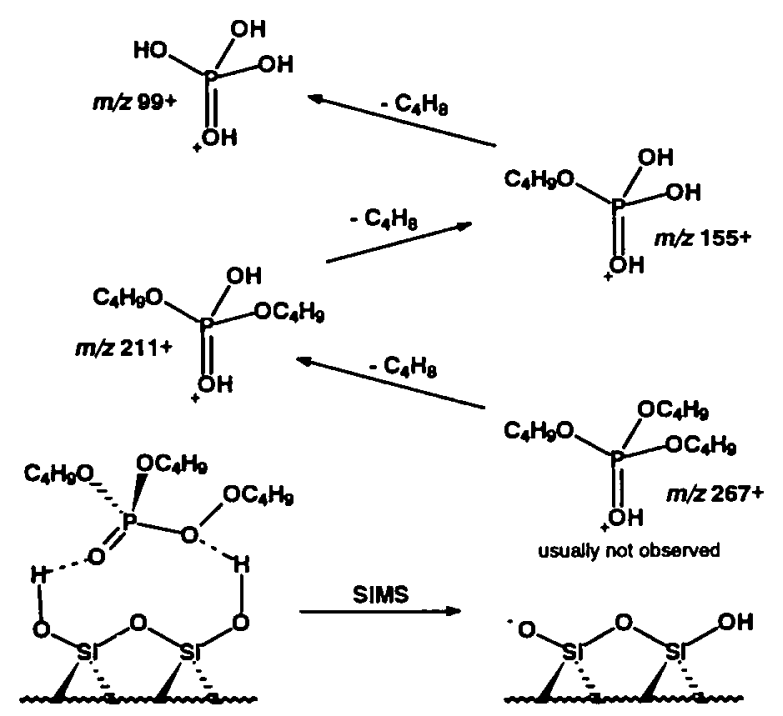

Figure 5. Proposed mechanism for the surface protonation of TBP and subsequent elimination of three $\mathrm{C}_{4} \mathrm{H}_{8}$ molecules. 
$[\mathrm{M}+\mathrm{H}]^{+}$is observed only occasionally at very low abundance in the SIMS spectra of TBP; in this case, the largest fraction of the ion current has been shifted to $m / z 99^{+}$, which means that the initially formed [M + $\mathrm{H}]^{+}$possessed sufficient internal energy for the occurrence of three $\mathrm{C}_{4} \mathrm{H}_{8}$ eliminations.

\section{Tributyl Phosphite Model for Tri-n-butyl Phosphate Reduction}

If TBP is reduced during the production of $m / z 137^{+}$, then an intermediate or transition state that resembles tributyl phosphite presumably would be involved. Accordingly, tributyl phosphite was examined on basalt and on the iron oxide powders to see if it exhibited behavior similar to that of TBP. The resultant SIMS spectra were remarkably similar to TBP on reducing surfaces: an abundant $m / z 137^{+}$is interpreted in terms of tributyl phosphite undergoing $\mathrm{H}^{-}$abstraction, followed by the elimination of two $\mathrm{C}_{4} \mathrm{H}_{8}$. These observations support the contention that TBP undergoes a similar process subsequent to reduction. It is noteworthy that a low abundance ion series that corresponds to $\mathrm{H}^{\sim}$ abstraction and subsequent loss of one and two $\mathrm{C}_{4} \mathrm{H}_{8}$ molecules also is observed in the methane $\mathrm{CI}$ spectrum of tributyl phosphite. One salient difference was observed when the SIMS spectra of TBP were compared with that of tributyl phosphite: the latter has an abundant $m / z 83^{+}$, which corresponds to the protonation of tributyl phosphite followed by the elimination of three $\mathrm{C}_{4} \mathrm{H}_{8}$ molecules. These ions constitute the major ion series in the CI mass spectrum of tributyl phosphite, but are not present in abundance in the SIMS spectra of TBP.

The observation of $m / z 99^{+}\left(\mathrm{H}_{4} \mathrm{PO}_{4}^{+}\right)$in the SIMS spectra of tributyl phosphite indicates that some of the tributyl phosphite has undergone oxidation on the surface of $\mathrm{FeO}, \mathrm{Fe}_{2} \mathrm{O}_{3}$, and the basalt samples. This finding is surprising in the case of $\mathrm{FeO}$, which would be difficult to reduce; however, it is possible that the oxidation of tributyl phosphite is the result of more oxidized Fe species present on the FeO surface. It is of interest that $m / z 153^{+}$also is observed in the SIMS spectra of tributyl phosphite on $\mathrm{FeO}$ and $\mathrm{Fe}_{2} \mathrm{O}_{3}$; this also is interpreted in terms of tributyl phosphite undergoing oxidation followed by hydride abstraction on the iron oxide surfaces.

\section{Structure of $m / z 125^{+}, 217^{+}, 235^{+}$Observed in the Secondary Ion Mass Spectrometry Spectra of Tri-n-butyl Phosphate}

$m / z 125^{+}, 217^{+}$, and $235^{+}$were observed reproducibly in the SIMS spectra of basalt, $\mathrm{FeO}$, and $\mathrm{Fe}_{2} \mathrm{O}_{3}$ that had been exposed to TBP. These ions are not considered to be important to arguments that relate to the reduction, hydride abstraction, or oxidation of TBP; nevertheless, they do constitute part of the signature for TBP on environmental samples, and hypotheses have been suggested with regard to their origin.

$m / z 125^{+}$is observed at low abundance in the EI and CI mass spectra of TBP; its abundance is normally modest in the SIMS spectrum also, but it can be as high as $15 \%$ (relative to $m / z 99^{+}$). The ion was assigned the structure of protonated vinyl phosphoric acid based on the results of a tandem mass spectrometry study that showed that collisionally activated $m / z$ $125^{+}$will eliminate $\mathrm{C}_{2} \mathrm{H}_{2}$ to form $\mathrm{m} / z$ 99 ${ }^{+}$[14]. The tandem mass spectrometry study did not identify any parent ions for $m / z 125^{+}$, however. One possibility is that $m / z 125^{+}$may arise via the loss of $\mathrm{C}_{2} \mathrm{H}_{6}$ from $[\mathrm{M}+\mathrm{H}]^{+}$to form $m / z 237^{+}$, which then undergoes the sequential elimination of two $\mathrm{C}_{4} \mathrm{H}_{8}$ molecules to form $181^{+}$and finally $125^{+}$. All of these ions are observed at low abundance, but above the background in the methane CI spectrum, and this explanation would support the protonated vinyl phosphoric acid structure proposed earlier. An alternative explanation would be the elimination of $\mathrm{C}_{2} \mathrm{H}_{4}$ from the $[\mathrm{M}-\mathrm{H}]^{+}$ to form $m / z 237^{+}$, which then eliminates two $\mathrm{C}_{4} \mathrm{H}_{8}$; this is in some ways a more plausible explanation because $\mathrm{C}_{2} \mathrm{H}_{4}$ could be eliminated via a six-membered transition state. We do not favor the latter explanation, however, because an abundant $\mathrm{m} / z 153^{+}$(signature for $[\mathrm{M}-\mathrm{H}]^{+}$) is not observed with abundant $\mathrm{m} / \mathrm{z}$ $125^{+}$in the SIMS experiments.

The elimination of two carbons from TBP molecular ion species that leads to $m / z 125^{+}$draws additional support from the EI mass spectrum. The TBP molecular ion undergoes elimination of the $\mathrm{C}_{2} \mathrm{H}_{5}$ radical to form $\mathrm{m} / \mathrm{z} 237^{+}$, which then sequentially eliminates two $\mathrm{C}_{4} \mathrm{H}_{8}$ to form $\mathrm{m} / z 181^{+}$and finally $125^{+}$. All of these ions are observed at low abundance in the EI spectrum.

The $m / z 235^{+}$ion is observed in the SIMS spectra of TBP, which contain evidence for reduction, and is also observable in the CI mass spectrum of tributyl phosphite. The explanation for $m / z 235^{+}$in the CI experiment is attachment of $\mathrm{C}_{3} \mathrm{H}_{5}^{+}$to tributyl phosphite to form $m / z 291^{+}$(not observed), which then undergoes the sequential elimination of three $\mathrm{C}_{4} \mathrm{H}_{8}$ to form $\mathrm{m} / \mathrm{z} 235^{+}, 179^{+}$, and $123^{+}$(all ions observed at low abundance in the CI spectrum). An analogous process could occur in the SIMS analyses: abundant hydrocarbons are present on the mineral surfaces, and $m / z 41^{+}$is the base peak in many of the SIMS spectra collected in our laboratory. Thus, formation of $\mathrm{m} / \mathrm{z}$ $235^{+}$would require reduction of TBP and proximity to a source of $\mathrm{C}_{3} \mathrm{H}_{5}^{+}$. One problem with this explanation is that ions at $\mathrm{m} / z 179^{+}$and $123^{+}$are not observed in the SIMS spectrum of tributyl phosphite: these ions were observable in the $\mathrm{CI}$ spectrum and correspond to sequential losses of two additional $\mathrm{C}_{4} \mathrm{H}_{8}$ molecules.

$\mathrm{m} / \mathrm{z} 217^{+}$also is observed frequently in the SIMS spectra of TBP. The best hypothesis for this ion is that it is formed by attachment of $\mathrm{Na}^{+}$to tributyl phos- 
phite to form $m / z 273^{+}$(not observed), which then eliminates $\mathrm{C}_{4} \mathrm{H}_{8}$ to produce $217^{+}$. However, the anticipated eliminations of a second and third $\mathrm{C}_{4} \mathrm{H}_{8}$ molecule (to form $\mathrm{m} / z \quad 161^{+}$and $105^{+}$) are not observed, and hence this explanation is not entirely satisfactory.

\section{Conclusions}

The SIMS spectrum of TBP on mineral samples, acquired by using a molecular primary ion under low beam current conditions, is indicative of whether the TBP is in contact with reducing surface sites, protonating sites, or sites that promote hydride abstraction [presumably Fe(III)]. Similarly, the SIMS spectrum of tributyl phosphite is influenced by sites where tributyl phosphite can be oxidized. This indicates that static SIMS of TBP and tributyl phosphite have the potential to characterize the chemical nature of mineral surfaces and the mode of contaminant-surface interaction. This information is important because the oxidization-reduction nature of the surfaces of mineral samples has important bearing on the binding of contaminants in the environment. This work raises the possibility that SIMS analysis of organophosphates other than TBP could be used to characterize surfaces that would be less reductive than the basalt samples described herein.

\section{Acknowledgment}

The authors thank Del Miley for performing the SEM/EDS analyses, Marnie Cortez for SIMS data acquisition, and Anita Gianotto for assistance with data reduction. This work was supported by the U.S. Department of Energy, Office of Technology Development, DOE Idaho Operations Office (Contract DE-AC-07761D01570).

\section{References}

1. Schulz, W. W.; Navratil, J. D., eds. Science and Technology of Tributyl Phosphate, Volume l. Synthesis, Properties, Reactions and Analysis; CRC Press: Boca Raton, FL, 1984.

2. Hanford Site Sampling and Analysis Data Document; Report EGG-ES-7953; US Department of Energy: Washington, DC, August 1988; Vol. 1, pp. 4-114 and 4-215; Vol. 1A, pp 4-474, 4-586, and 4-588; Addendum, November 1988, pp 4-88 and 4-209.

3. Reidel, S. P.; Lindsey, K. A.; Fecht, K. R. Field Trip Guide to the Hanford Site; Report WHC-MR-0391; US Department of Energy: Washington, DC, November 1992.

4. Brown, G. M. In The Poldernant Treatise on Rocks of Basaltic Composition, Vol. 1; Hess, H. H.; Poldervaart, A., Eds.; Interscience Publishers: New York, 1962; p 103.

5. Unger, S. E.; Vincze, A.; Cooks, R. G.; Chrisman, R.; Rothman, L. D. Anal. Chem. 1981, 53, 976-981.

6. Day, R. J.; Unger, S. E.; Cooks, R. G. Anal. Chem. 1980, 52, 557A-572A.

7. Appelhans, A. D.; Dahl, D. A.; Delmore, J. E. Anal. Chem. 1990, 62, 1679-1686.

8. Delmore, J. E.; Appelhans, A. D.; Peterson, E. S. Int. I. Mass Spectrom. Ion Processes 1991, 108, 179-187.

9. Briggs, D.; Hearn, M. J. Vaculmm 1986, 36, 1005-1010.

10. Winger, B. E.; Hand, O. W.; Cooks, R. G. Int. J. Mass Spectrom. Ion Processe's 1988, 84, 89-100.

11. Appelhans, A. D.; Dahl, D. A.; Delmore, J. E.; Groenewold, G. S.; Ingram, J. C. Book of Abstracts PITTCON 94; Chicago, IL, February 27-March 3, 1994; Abstract 1229.

12. (a) Hanke, W.; Wernisch, J.; Poehn, Ch. X-Ray Spectrom. 1985, 14, 43-47; (b) Poehn, Ch.; Wernisch, J.; Hanke, W. X-Ray Spectrom. 1985, 14, 120-124.

13. NIST Standard Reference Database 1A, NIST/EPA/NIH Mass Spectral Database, PC Version 4.0; Standard Reference Data Program; US Department of Commerce, National Institute of Standards and Technology: Gaithersburg, MD, May 1992.

14. D’Agostino, P. A.; Provost, L. R. Tandem Mass Spectrometric Analysis of Phosphate Esters; Suffield Report 581; Defense Research Establishment Suffield: Ralston: Alberta, Canada, March 1993. 